\title{
Relação entre Barreiras de Entrada e o Retorno Empresarial no Mercado Brasileiro a partir de Dados das Demonstrações Contábeis
}

\author{
Luiz Cláudio Louzada \\ Flávia Zóboli Dalmácio \\ Dimitri Pinheiro de Sant'Anna \\ Aridelmo José Campanharo Teixeira
}

\section{RESUMO}

$\mathrm{O}$ artigo busca relacionar fatores da teoria da estratégia do posicionamento a parâmetros das demonstrações contábeis, mais especificamente utiliza-se de medidas contábeis para verificar, de forma geral, a aderência da teoria da estratégia do posicionamento no mercado brasileiro, por meio da relação entre a variável tamanho (proxy para Barreira de Entrada) e o retorno da unidade empresarial. Na pesquisa bibliográfica, a preocupação foi relacionar os conceitos existentes na teoria contábil com os conceitos de estratégia competitiva da escola do posicionamento. Por conseguinte, aplicouse um teste empírico, utilizando inferências estatísticas entre duas médias para verificar a existência de relação positiva entre as variáveis tamanho (Barreiras de Entrada) e o retorno das unidades empresariais no mercado brasileiro, a partir de informações contábeis. Os resultados dos testes demonstram que os retornos das empresas de maior tamanho são superiores aos das empresas menores no mercado brasileiro. Esse resultado insere indicativos da relevância da informação contábil, quando relacionada com a estratégia competitiva da escola do posicionamento.

Palavras-chave: teoria estratégica do posicionamento; barreiras de entrada; retorno empresarial; demonstrações contábeis; mercado brasileiro.

\begin{abstract}
This paper aims to relate factors of the strategy theory from positioning, to the parameters of accounting demonstrations, more specifically, it makes use of accounting criteria to verify, in general terms, whether those theories may be applied to the Brazilian market through the relation between barriers to entry (size) and the managerial return. In this bibliographical research, the main concern was to relate the existing concepts in the accounting theory with the competitive strategy concepts of the positioning theory. Furthermore, an empirical test was applied making use of statistical inferences between two averages to verify the existence of positive relations among the variables, size (barriers to entry) and the managerial return into the Brazilian market, using accounting data. The results of these tests show that the return of the bigger companies is superior to the smaller ones. This result includes indicatives for accounting information relevance when related to the competitive strategy of the positioning theory.
\end{abstract}

Key words: the strategy theory from positioning; barrie to entry; the managerial return; accounting demonstrations; brazilian market. 


\section{INTRODUÇÃO}

A Teoria da Organização Industrial é formada por um aparato analítico essencial para a percepção das relações entre a unidade empresarial e o mercado, cujo foco está nas influências que a estrutura do mercado causam nas organizações. Byrns e Stone (1996) enfatizaram que as estruturas de mercado determinam quase rigidamente a conduta de cada firma (decisão de produção e comportamento dos preços) que gera um desempenho global da indústria (eficiência e lucratividade). Tal abordagem é denominada de paradigma Estrutura-Conduta-Desempenho ${ }^{(1)}$.

A essência desse paradigma consiste em relacionar o desempenho de uma empresa no mercado como variável dependente das características do ambiente em que ela está exposta (Porter, 1983). Bain afirmou (como citado em Porter, 1981):

Os principais elementos identificados nesta estrutura como importantes para o desempenho das primeiras pesquisas sobre Organização Industrial são as barreiras de entrada, o tamanho e a quantidade da distribuição de firmas, diferenciação de produtos e a flexibilidade da demanda. Outro aspecto importante é a visão de que a estrutura determina a conduta (estratégia) a qual por sua vez determina o desempenho. Pode-se ignorar a conduta e olhar diretamente para a estrutura da empresa numa tentativa de explicar o desempenho (p. 611).

Michael Porter foi responsável por traduzir os fatores estilizados da organização industrial para o mundo das empresas, estabelecendo condições para a obtenção de vantagens competitivas que nada mais são do que assimetrias em relação aos concorrentes. As estratégias das empresas podem alterar a especificidade dos ativos (Farina, Azevedo, \& Saes, 1999).

A intensidade das forças competitivas determina a habilidade das firmas de ganhar, em média, retornos sobre o investimento acima do custo de capital. A intensidade de cada uma dessas cinco forças é função da estrutura da indústria ou das características econômicas e técnicas (Porter, 1983).

Fundamentalmente, o objetivo da Contabilidade é tornar as atividades empresariais compreensíveis, ou seja, o propósito central da Contabilidade é tornar possível aos usuários alcançar um julgamento calculado do sucesso de uma empresa na execução de suas atividades (Chambers, 1966). 
O arcabouço teórico da Contabilidade norteia e sustenta as práticas contábeis, focando a utilidade da informação. Os procedimentos e práticas racionalmente deduzidos ou testados objetivam: identificar, mensurar e evidenciar a informação econômica para decisão e julgamento por parte dos usuários da informação.

Philips (1963) afirmou que o arcabouço teórico da Contabilidade é sustentado pelos Postulados Ambientais da Continuidade e da Entidade. De acordo com Iudícibus, Martins e Gelbcke (2003), pelo Postulado da Entidade, "a contabilidade é mantida para as Entidades; os sócios ou quotistas destas não se confundem, para efeito contábil, com aquelas (...)". O Postulado da Continuidade da entidade, em essência, refere-se ao ambiente em que as entidades atuam e à forma com que elas operam nesse mercado. Iudícibus et al. (2003) acrescentaram: "para a Contabilidade, a Entidade é um organismo vivo que irá viver (operar) por um longo período de tempo (indeterminado) até que surjam fortes evidências em contrário (...)" (p. 55).

A definição ideal do objetivo da Contabilidade é fornecer informação útil, preditiva e específica para usuários específicos tomarem decisões. Para tanto são necessárias algumas normas e procedimentos, como os postulados, princípios e convenções, a fim de nortear a prática contábil ${ }^{(2)}$.

Este trabalho baseia-se, portanto, em uma relação entre duas áreas do conhecimento: estratégia competitiva e informações contábeis, conforme demonstrado, na Figura 1:

\section{Figura 1: Relação Teórica entre os Campos do Conhecimento}

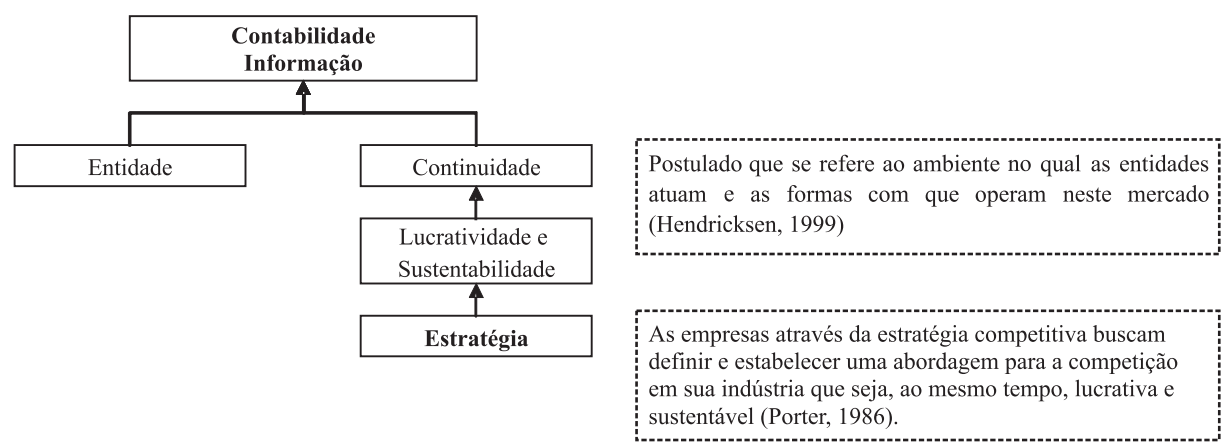

Fonte: Elaborada pelos autores.

A Estratégia ${ }^{(3)}$ Competitiva, segundo Porter (1986), "[...] preocupa-se em estabelecer uma abordagem para a competição de uma unidade empresarial em sua indústria, que seja, ao mesmo tempo, lucrativa e sustentável" (p. 22). Suas 
pesquisas objetivavam analisar a estrutura de um determinado setor e a capacidade que tem uma unidade empresarial de ser lucrativa e sustentável nesse setor.

De acordo com Iudícibus (2000),

um postulado pode ser definido como uma proposição ou observação de certa realidade que pode ser considerada não sujeita a verificação, ou axiomática. Normalmente, a categoria de postulado, em Contabilidade, abarca uma área de atração mais ampla do que a da própria disciplina e relaciona-se com certos aspectos "ambientais" ou que cercam o campo e as condições em que a Contabilidade deve atuar (p. 46).

Segundo Iudícibus et al. (2003),

os postulados ambientais enunciam, solenemente, condições sociais, econômicas e institucionais dentro das quais a Contabilidade atua; escapam ao restrito domínio da Contabilidade, para inserir-se no mais amplo feudo da Sociologia Comercial e do Direito, bem como da Economia e outras ciências. Predispõem a Contabilidade no que se segue, a assumir esta ou aquela postura, embora o condicionamento não seja tão restrito quanto se possa imaginar (p. 53).

Portanto, se os Postulados ambientais sustentam o arcabouço teórico da Contabilidade, influenciando a configuração da estrutura e informações contempladas nas demonstrações contábeis, então estas deveriam ser capazes de refletir os aspectos estratégicos da unidade empresarial, visto que a Continuidade empresarial pressupõe lucratividade e sustentabilidade ao longo do tempo. É nesse ponto que os Postulados contábeis guardam relações teóricas com as premissas da escola do Posicionamento.

Porter (1983) afirmou que a intensidade das forças competitivas determinam a habilidade das firmas de ganhar, em média, retornos sobre o investimento acima do custo de capital. A intensidade dessas forças é função da estrutura da indústria, ou das características econômicas e técnicas da unidade empresarial.

A manifestação das forças competitivas é uma função da estrutura industrial, ou das características técnicas e econômicas subjacentes à indústria. De acordo com Porter (1983),

As cinco forças determinam a rentabilidade da indústria porque influenciam os preços, os custos e os investimentos necessários das empresas em uma indústria - os elementos de retorno sobre o investimento. $\mathrm{O}$ poder do comprador influencia os preços que as empresas podem cobrar [...] da mesma forma que a ameaça de substituição. O poder dos compradores também pode influenciar os custos e os investimentos, porque compradores poderosos 
exigem serviços dispendiosos. O poder de negociação dos fornecedores determina os custos das matérias-primas e de outros insumos. A intensidade da rivalidade influencia os preços assim como os custos da concorrência em áreas como fábrica, desenvolvimento de produto, publicidade e força de vendas. A ameaça de entrada coloca um limite nos preços e modula o investimento exigido para deter entrantes (grifo nosso) (p. 174).

\section{Questão Problema}

Dentro desse contexto, a partir de dados contidos nas demonstrações contábeis, procurar-se-á, no transcorrer deste trabalho, responder à seguinte questão: qual a aderência da estratégia competitiva (teoria do posicionamento) no mercado brasileiro no quesito 'barreiras de entrada'? Especificamente, busca-se verificar se existe relação positiva entre tamanho empresarial (barreira de entrada) e o retorno das unidades empresariais listadas no mercado brasileiro.

\section{Objetivos da Pesquisa}

Objetivo geral. Como decorrência do problema apresentado, o objetivo geral desta pesquisa consiste em: identificar se os conceitos da teoria do posicionamento são aderentes ao mercado brasileiro, no quesito 'barreira de entrada', a partir do estudo da relação entre o tamanho (proxy para barreira de entrada) e o retorno das unidades empresariais no mercado brasileiro.

\section{Formulação da Hipótese}

Thompson e Formby (1998) destacaram que a maior parte das indústrias e mercados se caracterizam pela seguinte cadeia de relações de causa e efeito (Figura 2):

\section{Figura 2: Relação Causa Efeito nos Mercados}

\begin{tabular}{|c|c|c|c|}
\hline $\begin{array}{l}\text { maior } \\
\text { participação } \\
\text { no mercado }\end{array}$ & $\begin{array}{l}\text { maior volume } \\
\text { acumulado de } \\
\text { vendas }\end{array}$ & $\begin{array}{l}\text { menores custos } \\
\text { unitários } \\
\text { de produção }\end{array}$ & $\begin{array}{l}\text { maior } \\
\text { lucratividade }\end{array}$ \\
\hline
\end{tabular}

Fonte: Thompson e Formby (1998).

As implicações dessa cadeia mostram que o tamanho das empresas tem relação positiva com os retornos empresariais, ou seja, maiores empresas apresentam retornos superiores às empresas de menor tamanho. 
Com o objetivo de verificar se tal suposição pode ser confirmada no mercado brasileiro, configurou-se a seguinte hipótese: as maiores unidades empresariais possuem em média retornos superiores, comparadas com as unidades empresariais menores, no mercado brasileiro.

\section{Metodologia da Pesquisa}

Este trabalho resulta de uma pesquisa exploratória, que busca estabelecer uma relação teórica entre conceitos de áreas distintas do campo empresarial, cujo foco se volta para a contribuição da capacidade informativa (utilidade) das demonstrações contábeis.

A fundamentação metodológica foi definida como pesquisa exploratória, assim definida por Beuren (2003):

As pesquisas exploratórias têm como principal finalidade desenvolver, esclarecer e modificar conceitos e idéias, com vistas à formulação de problemas mais precisos ou hipóteses pesquisáveis para estudos posteriores [...]. Pesquisas exploratórias são desenvolvidas com o objetivo de proporcionar visão, de tipo aproximativo, acerca de determinado fato. Este tipo de pesquisa é realizado especialmente quando o tema escolhido é pouco explorado [...]. Muitas vezes as pesquisas exploratórias constituem a primeira etapa de uma investigação mais ampla [...]. O produto final deste processo passa a ser um problema mais esclarecido, possível de investigação mediante procedimento mais sistematizado (grifos nossos) (p. 80).

De acordo com Marconi e Lakatos (1999), este tipo de pesquisa de base exploratória se define basicamente pela prática da empírica, onde se obtêm frequientemente descrições tanto quantitativas quanto qualitativas do objeto de estudo: ao pesquisador cabe "conceituar as inter-relações das propriedades do fenômeno, fato ou ambiente observado" (p. 87).

Segundo Martins (2000), na pesquisa exploratória trata-se “de abordagem adotada para a busca de maiores informações sobre determinado assunto. Possui um planejamento flexível, e é indicada, quando se tem pouco conhecimento do assunto. Tem a finalidade de formular problemas e hipóteses para estudos posteriores" (p. 30).

\section{Limitações da Pesquisa}

As principais limitações deste trabalho estão relacionadas, a seguir. 
(1) Características dos dados no mercado. Os dados utilizados para o estudo não foram setorizados. $\mathrm{O}$ objeto de estudo da escola do posicionamento tem como unidade de estudo o setor. Entretanto a segmentação do mercado em setor torna disponíveis poucos dados para análise, o que também poderia ser uma limitação para o estudo das teorias da estratégia do posicionamento.

(2) Delimitação da pesquisa. O estudo busca estabelecer relação entre a característica tamanho (proxy para barreira de entrada) e o retorno da unidade empresarial. Limita-se, portanto, ao estudo de uma única força. Entretanto, "[...] a característica tamanho garante uma melhor posição da unidade empresarial comparativamente a seus concorrentes, fornecedores e clientes" (Thompson \& Formby, 1998, p. 170).

(3) Diferenciação entre os conceitos lucro contábil e lucro econômico. Relacionar as teorias do posicionamento (fundamentações em teorias econômicas e administrativas), com as métricas das demonstrações contábeis, gera uma limitação a partir de conceitos distintos sobre os resultados empresariais ${ }^{(4)}$.

Contudo tais limitações não eliminam a possibilidade da obtenção de certas evidências úteis como subsídio para futuras pesquisas. Empregando tal metodologia em setores específicos, com amostras significativas, podem-se obter maiores aderências à teoria do posicionamento e estabelecer relação destas com as medidas contábeis no mercado brasileiro.

\section{Relacionando as Demonstrações Contábeis com a Estratégia COMPETITIVA}

A Contabilidade é uma linguagem que expressa as relações patrimoniais no ambiente empresarial, configurando-se em um instrumento para a eficiência na alocação de recursos; daí a sua importância numa economia de mercado. Sem a informação apropriada, o risco aumenta e, devido ao custo de capital, há um reflexo nos preços (Limeira, 2004). Portanto a utilidade da informação contábil está vinculada ao suporte para a efetivação de contratos e para a comprovação das relações estabelecidas, sendo fundamental para o controle das atividades econômicas e para avaliação de desempenho. Assaf Neto (2002) comentou que

[...] as decisões financeiras tomadas regularmente por uma empresa se resumem na captação de recursos [...] e na aplicação dos valores levantados. Os montantes determinados por esta decisão, assim como suas diferentes naturezas, estão apuradas nos ativos (investimentos) e passivos 
(financiamentos) contabilizados pela empresa. São decisões que toda empresa toma de maneira contínua e inevitável, definindo sua estabilidade financeira e atratividade econômica. [...] um dos aspectos mais importantes de medição do desempenho de uma empresa centra-se na comparação entre o retorno que os ativos (investimentos) são capazes de produzir em determinado período e custo dos recursos alocados para seu financiamento (grifos nossos) (p. 37).

As decisões na unidade empresarial podem ser observadas na estrutura das demonstrações contábeis, que evidenciam as alterações ocorridas nos ativos, lucros e dividendos ao longo dos anos. Neste contexto econômico empresarial, Assaf Neto (2002) teceu a seguinte abordagem sobre a unidade empresarial:

[...] a empresa pode ser compreendida como uma unidade tomadora de decisões econômicas (por exemplo: definir a combinação ideal de produção e preço) voltada para a realização do lucro por meio de venda de bens e serviços. [...] uma preocupação essencial do analista deve ser a de conhecer mais detalhadamente a empresa e seu mercado de atuação de maneira a melhor avaliar suas decisões [...]. A análise de balanço torna-se bem mais consistente quando interpretada dentro das características do setor de atividade da empresa (grifos nossos) (p. 44).

As demonstrações contábeis traduzem tanto a posição de uma empresa num ponto no tempo (demonstrações estáticas) quanto suas operações ao longo de um período passado (demonstrações dinâmicas). Entretanto, o real valor das demonstrações contábeis está no fato de que elas podem ser utilizadas para ajudar a prever lucros e dividendos futuros. Do ponto de vista de um investidor, a prospecção de informações (tendências) futuras é tudo o que a análise das demonstrações contábeis objetiva, enquanto, do ponto de vista dos gestores, a análise das demonstrações financeiras é útil para ajudar a antecipar condições futuras, além de representar um ponto de partida para planejar medidas que afetarão o curso futuro dos eventos (Brigham, Gapenski, \& Ehrhardt, 2001). Essa percepção de prospecção da informação está baseada no contexto da estrutura empresarial.

A partir das relações dos índices de retorno sobre o investimento, Ronchi (1977) deduziu as seguintes características econômico-empresariais que se relacionavam com as medidas de margem e rotação: as características tecnológicas do processo realizado pela empresa em exame; e as características econômicas gerais e de mercado, nas quais o sistema empresarial está operando. 


\section{As características tecnológicas do processo determinam os seguintes elementos:}

(a.1) Instalações e maquinário necessário para a produção. (a.2) Estoques de matérias-primas, produtos em elaboração e produtos acabados estocados. (a.3) Duração dos ciclos de produção; e em conseqüência, também. (a.4) Os valores dos ativos totais (fixos e circulantes) exigidos para a produção. (a.5) O volume máximo de produção possível de se obter com as instalações consideradas.

\section{As características econômicas e do mercado, por sua vez, determinam os seguintes elementos:}

(b.1) Custos unitários das matérias-primas, do trabalho, energia e outros elementos auxiliares necessários para a transformação. (b.2) Preços atribuíveis à produção introduzida no mercado, tendo em conta a atitude de concorrência e o potencial dos compradores. (b.3) O custo total da produção prevista. (b.4) $\mathrm{O}$ valor total das vendas previstas (preço de venda previsto para o volume de produção previsto). (b.5) Lucro líquido previsto do período (valor total das vendas previstas menos custo total de produção previsto) (p. 35).

Pelos elementos (a.4), (b.4) e (b.5), é possível obter os valores da margem de lucro sobre as vendas (b.5) / (b.4) e da rotação dos ativos (b.4) / (a.4); enfim, calcular a lucratividade global da empresa (b.5) / (a.4).

Portanto, considerando que o desenvolvimento da estratégia competitiva empresarial se confira a partir das ameaças e oportunidades existentes no mercado, em relação à potencialidade gerada pela estrutura empresarial, a composição dos ativos da organização e sua utilização poderão estar refletidos nas demonstrações dos resultados empresariais. Considerando, ainda, que a lucratividade empresarial consiste no resultado das políticas e decisões tomadas, podemos inferir que os índices de lucratividade mostram os efeitos combinados da gestão dos ativos e da formação de resultados empresariais ${ }^{(5)}$.

\section{Relação entre Barreira de Entrada e o Retorno Empresarial no Mercado Brasileiro}

Neste tópico, procurar-se-á investigar a relação entre o tamanho (proxy para Barreiras de Entrada) e seu retorno, a partir de parâmetros contidos nas demonstrações contábeis. A questão de pesquisa consiste em identificar: Qual a aderência da estratégia competitiva (teoria do posicionamento) no mercado 
brasileiro no quesito "barreiras de entrada"? Especificamente, busca-se verificar se existe relação positiva entre o tamanho empresarial (barreira de entrada) e o retorno das unidades empresariais listadas no mercado brasileiro.

Byrns e Stone (1996) afirmou que "as estruturas de mercado determinam quase rigidamente a conduta de cada firma (decisão de produção e comportamento dos preços); que gera um desempenho global da indústria (eficiência e lucratividade). Tal abordagem é denominada de paradigma Estrutura-Conduta-Desempenho" (p. 262).

A essência do paradigma da Organização Industrial consiste em relacionar o desempenho de uma empresa no mercado como variável dependente das características do ambiente em que ela está exposta (Porter, 1983).

Bain (como citado em Porter, 1981) complementaram:

Os principais elementos identificados nesta estrutura como importantes para o desempenho das primeiras pesquisas sobre Organização Industrial, são as barreiras de entrada, o tamanho e a quantidade da distribuição de firmas, diferenciação de produtos e a flexibilidade da demanda. Um último aspecto importante do Paradigma de Bain/Mason é a visão de que a estrutura determinava a conduta (estratégia), a qual por sua vez, determinava o desempenho. Pode-se ignorar a conduta e olhar diretamente para a estrutura da empresa numa tentativa de explicar o desempenho (grifos nossos) (p. 611).

\section{Hipótese da Pesquisa}

Supõe-se, portanto, que o tamanho das empresas tem relação positiva com os retornos empresariais, ou seja, maiores empresas apresentam retornos superiores aos das empresas de menor tamanho. Com o objetivo de verificar se tal suposição pode ser confirmada no mercado brasileiro, configurou-se a seguinte hipótese: as maiores unidades empresariais possuem retornos superiores, se comparadas às unidades empresariais menores no mercado brasileiro.

Ho.: As maiores unidades empresariais apresentam, em média, retornos superiores $\left(\mu_{R}\right)$, se comparados com os retornos $\left(\mu_{r}\right)$ das menores unidades empresariais, no mercado brasileiro.

$$
H_{0}: \mu_{R} \geq \mu_{r}
$$


H1: As maiores unidades empresariais não apresentam, em média, retornos superiores $\left(\mu_{R}\right)$, se comparados com os retornos $\left(\mu_{r}\right)$ das menores unidades empresariais, em média, no mercado brasileiro.

$$
H_{1}: \mu_{R}<\mu_{r}
$$

Para testar essa hipótese, foram relacionadas as empresas listadas na BOVESPA, no período de 1998 a 2002, e coletados os dados das demonstrações contábeis: Total do ativo, Receita de vendas e Retorno sobre o ativo. O Total dos ativos e Receita de vendas foram utilizados como variáveis representativas do tamanho das empresas (proxy para barreira de entrada).

A estatística de teste selecionada consiste na comparação das médias dos retornos entre os grupos denominados maiores unidades empresariais e menores unidades empresariais, criados a partir das variáveis contábeis: Total do ativo e Receita de vendas. Enquanto o retorno sobre o ativo será utilizado para verificar a hipótese a ser investigada no trabalho, a comparação do retorno entre os dois grupos será feita a partir do teste de inferência entre duas amostras.

\section{Dados e Metodologia de Tratamento}

\section{Seleção da Amostra e Tratamento dos Dados}

A amostra deste trabalho foi extraída do banco de dados da Economática, empresa especializada em informações para o mercado de capitais. Os dados referem-se às empresas que tiveram ações negociadas na Bolsa de Valores de São Paulo, no período de janeiro de 1998 a dezembro de 2002.

Limitou-se o escopo deste trabalho aos exercícios de 1998 a 2002, devido à disponibilidade de dados, bem como à maior estabilidade econômica brasileira após o Plano Real: “A comparação entre números influenciados por uma inflação de quatro dígitos ao ano e outros com inflação em patamares de dois (ou menos) dígitos poderia distorcer em muito os resultados e/ou desviar a atenção dos mesmos" (Santanna, Teixeira, \& Louzada, 2003, p. 5).

Foram selecionados dados do Total dos ativos, Receita de vendas e Retornos sobre o ativo das empresas que apresentaram informações em todos os exercícios do período selecionado, calculando-se a média dos referidos períodos.

Após esse procedimento, verificou-se a existência de outliers e adotou-se como critério de corte o método 'trimming', que exclui n observações superiores e 
inferiores da amostra (Lopes, 2001). Assim foram retiradas as treze observações maiores e menores das amostras.

\section{Estatística Descritiva}

Os dados foram listados em ordem crescente de Total de ativo e Receita de vendas, para seleção dos grupos caracterizados como 'maiores empresas' e 'menores empresas'. Foi utilizado, também, como critério de separação dos grupos, a mediana e a média e, em seguida, calculou-se a média dos retornos sobre os ativos de cada grupo.

São apresentadas, na Tabela 1, as estatísticas descritivas dos dados.

\section{Tabela 1: Estatística Descritiva da Amostra: \\ Média do Período (1998 - 2002)}

\begin{tabular}{|c|c|c|c|c|c|c|}
\hline Variáveis & $n$ & Média & Desvio padrão & Mediana & Máximo & Mínimo \\
\hline \multicolumn{7}{|l|}{ BOVESPA } \\
\hline Total dos ativos & 197 & $4.131 .858,0$ & $15.034 .028,8$ & $543.388,2$ & $153.292 .462,8$ & $8.902,8$ \\
\hline Volume de vendas & 197 & $1.288 .391,9$ & $3.633 .126,4$ & $324.810,4$ & $38.550 .330,0$ & 20,2 \\
\hline Retorno & 197 & $(0,14)$ & 6,82 & 0,86 & 12,66 & $(21,10)$ \\
\hline \multicolumn{7}{|c|}{ TAMANHO DO ATIVO } \\
\hline \multicolumn{7}{|c|}{ MEDIANA } \\
\hline \multicolumn{7}{|c|}{ Grupo: "menores empresas" } \\
\hline Tamanho do ativo & 99 & $187.474,74$ & $145.851,55$ & $143.185,60$ & $543.388,20$ & $8.902,80$ \\
\hline Retorno & 99 & $(1,41)$ & 7,68 & $(1,16)$ & 12,66 & $(21,10)$ \\
\hline \multicolumn{7}{|c|}{ Grupo: "maiores empresas" } \\
\hline Tamanho do ativo & 98 & $8.719 .551,73$ & $20.487 .135,65$ & $2.531 .112,10$ & $153.292 .462,80$ & $549.710,00$ \\
\hline Retorno & 98 & 1,15 & 5,57 & 1,85 & 11,53 & $(14,75)$ \\
\hline \multicolumn{7}{|l|}{ MEDIA } \\
\hline \multicolumn{7}{|c|}{ Grupo: "menores empresas" } \\
\hline Tamanho do ativo & 165 & $800.421,45$ & $956.298,52$ & $347.797,20$ & $3.965 .257,60$ & $8.902,80$ \\
\hline Retorno & 165 & $(0,45)$ & 7,15 & 0,54 & 12,66 & $(21,10)$ \\
\hline \multicolumn{7}{|c|}{ Grupo: "maiores empresas" } \\
\hline Tamanho do ativo & 32 & $23.156 .454,03$ & $31.497 .512,36$ & $9.804 .068,40$ & $153.292 .462,80$ & $4.708 .667,40$ \\
\hline Retorno & 32 & 1,50 & 4,51 & 1,61 & 11,19 & $(11,33)$ \\
\hline \multicolumn{7}{|c|}{ VOLUME DE VENDAS } \\
\hline \multicolumn{7}{|l|}{ MEDIANA } \\
\hline \multicolumn{7}{|c|}{ Grupo: "menores empresas" } \\
\hline Volume de vendas & 99 & $100.407,66$ & $84.979,83$ & $75.055,20$ & $324.810,40$ & 20,20 \\
\hline Retorno & 99 & $(1,38)$ & 7,61 & $(0,88)$ & 12,66 & $(21,10)$ \\
\hline \multicolumn{7}{|c|}{ Grupo: "maiores empresas" } \\
\hline Volume de vendas & 98 & $2.488 .498,36$ & $4.875 .301,68$ & $985.332,60$ & $38.550 .330,00$ & $336.532,60$ \\
\hline Retorno & 98 & 1,12 & 5,68 & 1,85 & 11,53 & $(16,03)$ \\
\hline \multicolumn{7}{|c|}{ MEDIA } \\
\hline \multicolumn{7}{|c|}{ Grupo: "menores empresas" } \\
\hline Volume de vendas & 161 & $326.595,13$ & $339.615,83$ & $180.767,20$ & $1.238 .733,00$ & 20,20 \\
\hline Retorno & 161 & $(0,70)$ & 7,21 & 0,09 & 12,66 & $(21,10)$ \\
\hline \multicolumn{7}{|c|}{ Grupo: "maiores empresas" } \\
\hline Volume de vendas & 36 & $5.589 .760,61$ & $7.078 .481,40$ & $3.119 .836,50$ & $38.550 .330,00$ & $1.373 .973,60$ \\
\hline Retorno & 36 & 2,38 & 3,88 & 2,20 & 11,19 & $(4,89)$ \\
\hline
\end{tabular}


Verificam-se algumas informações, que podem ser consideradas relevantes, sobre as empresas brasileiras, referentes à característica tamanho. Os dados refletem que, em média, os retornos sobre os ativos das maiores empresas são superiores aos retornos das empresas menores. Isso ocorre independentemente de se usar o volume de venda ou total de ativos como variáveis do tamanho da empresa e, ainda, média ou mediana como critério de segregação dos grupos de empresas.

O desvio padrão do Total dos ativos e Receita de vendas é superior no grupo das grandes empresas, demonstrando que tais variáveis estão mais dispersas no grupo das grandes empresas e mais concentradas no grupo das pequenas empresas, enquanto a medida de retorno apresenta uma maior dispersão nos dados no grupo das pequenas empresas.

\section{Teste de Normalidade dos Dados}

Para o teste de normalidade ${ }^{(6)}$, definiu-se como hipótese nula que as variáveis de teste - total do ativo, receita de vendas e retorno sobre o ativo - apresentavam distribuição normal. Após os testes, os seguintes resultados foram obtidos:

\section{Gráfico 1: Distribuição das Variáveis: Total do Ativo e Volume de Vendas}

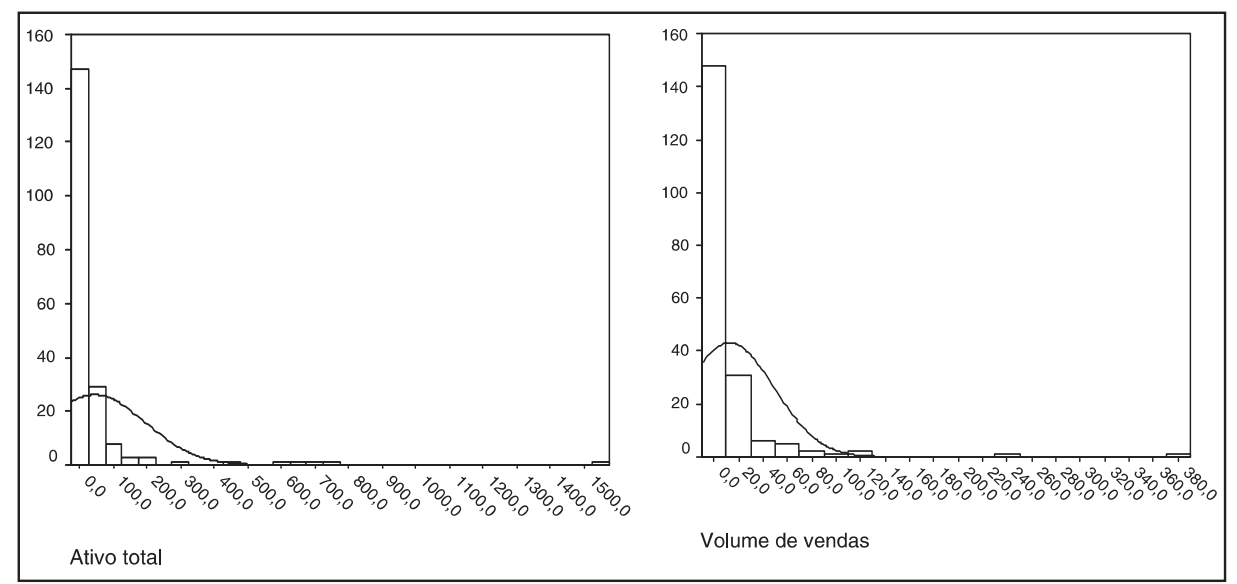

\section{Teste das Variáveis Tamanho}

Os gráficos da distribuição dos dados Receita de venda e Total dos ativos apresentam uma assimetria para a esquerda (negativamente assimétrica) (Gráfico 
1). Portanto, a mediana dos dados encontra-se à direita da média, o que é confirmado pelo teste de normalidade (Tabela 2).

Tabela 2: Teste de Normalidade - Ativo Total e Volume de Vendas

\begin{tabular}{|c|c|c|c|c|c|c|c|c|c|}
\hline \multicolumn{5}{|c|}{ Ativo total } & \multicolumn{5}{|c|}{ Volume de vendas } \\
\hline \multirow{2}{*}{$\mathrm{n}$} & \multicolumn{2}{|c|}{ Parâmetros da normal } & \multirow{2}{*}{ K-S Z } & \multirow{2}{*}{ Sig. } & \multirow{2}{*}{$\mathrm{n}$} & \multicolumn{2}{|c|}{ Parâmetros da normal } & \multirow{2}{*}{ K-S Z } & \multirow{2}{*}{ Sig. } \\
\hline & Média & Desv_Pad & & & & Média & Desv_Pad & & \\
\hline 197 & 4431858 & 15034029 & 5,39 & $<0,005$ & 197 & 1288392 & 3633126 & 5,07 & $<0,005$ \\
\hline
\end{tabular}

Nível de significancia: 0,05

O teste de Kolmogorov-Smirnov rejeitou a hipótese de que as variáveis ativo total e volume de vendas seguem distribuição normal (sig. < 0,005). Portanto, a partir dessa constatação, assume-se como critério para a formação dos grupos de teste a mediana e a média ${ }^{(7)}$.

\section{Teste da Variável Retorno}

Os gráficos a seguir (Gráfico 2) representam os dados da amostra completa, com 223 informações (esquerda), depois de retirados os 26 dados (direita) considerados outliers. Foram trabalhados 197 dados, que apresentaram uma aproximação à normalidade após esse procedimento (Tabela 3).

\section{Gráfico 2: Distribuição dos Retornos sobre o Ativo}

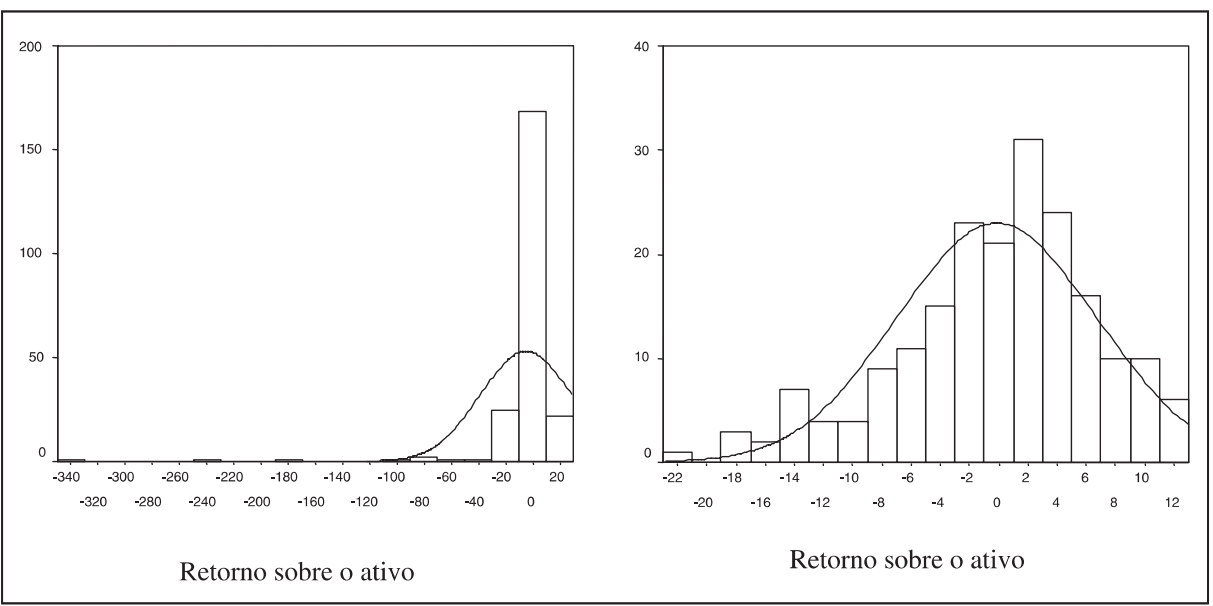


Tabela 3: Teste de Normalidade do Retorno sobre o Investimento

\begin{tabular}{|c|c|c|c|c|c|c|c|c|c|}
\hline \multicolumn{5}{|c|}{ Antes } & \multicolumn{5}{|c|}{ Depois } \\
\hline \multirow{2}{*}{$\mathrm{n}$} & \multicolumn{2}{|c|}{ Parâmetros da normal } & \multirow{2}{*}{$\mathrm{K}-\mathrm{S}$ Z } & \multirow{2}{*}{ Sig. } & \multirow{2}{*}{$\mathrm{n}$} & \multicolumn{2}{|c|}{ Parâmetros da normal } & \multirow{2}{*}{ K-S Z } & \multirow{2}{*}{ Sig. } \\
\hline & Média & Desv_Pad & & & & Média & Desv_Pad & & \\
\hline 223 & $-4,89$ & 33,51 & 4,48 & $<0,005$ & 197 & $-0,14$ & 6,82 & 1,04 & 0,23 \\
\hline
\end{tabular}

Nível de significancia: 0,05

Após a eliminação de outliers da amostra, os dados de retornos sobre os ativos apresentaram aproximação à distribuição normal, comprovada estatisticamente (sig. 0,23) ao nível de significância de 5\%.

Testou-se a normalidade dos retornos para os dados agrupados (grupos: maiores e menores empresas). Conforme disposto na Tabela 4:

\section{Tabela 4: Teste de Normalidade dos Grupos de Empresas}

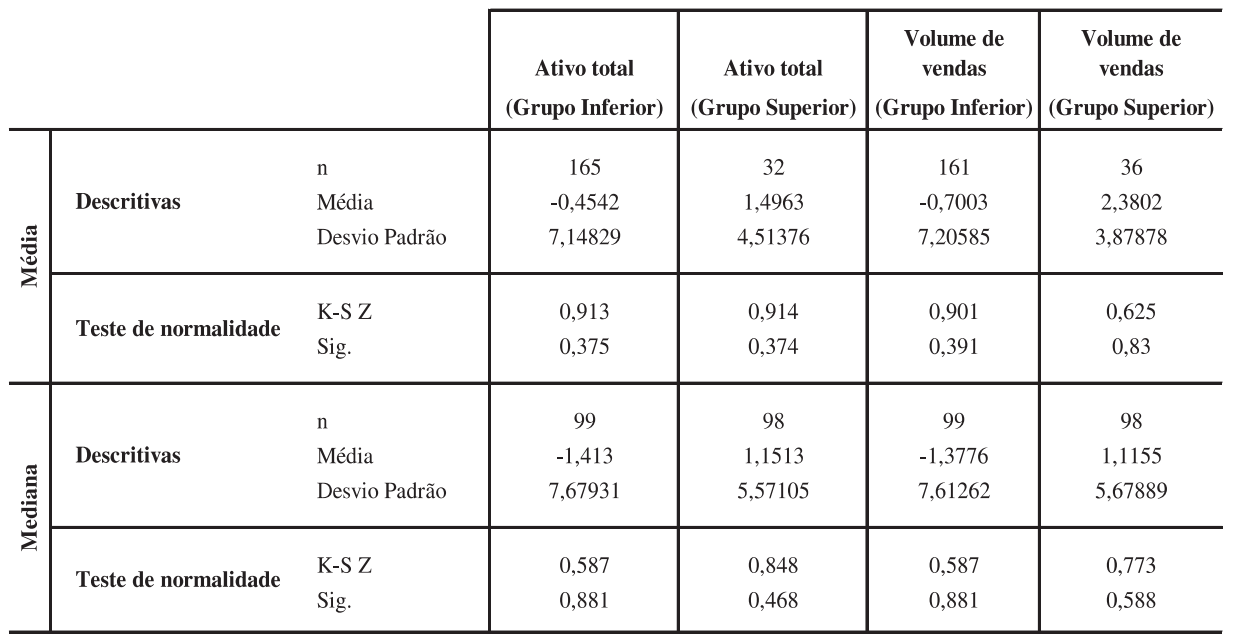

Nível de significancia: 0,05

O teste de normalidade de Kolmogorov-Smirnov, para verificar se os dados apresentam distribuição normal (Ho), demonstra que os grupos, subdivididos pelas médias e medianas, seguem distribuição aproximadamente normal ao nível de $5 \%$.

Outra suposição para uso do teste de diferença entre médias de grupos diferentes é a independência entre si. Dado que os valores do grupo das empresas maiores e os valores dos grupos menores empresas não agem com influência um do outro, pode-se, então, utilizar o teste $t$ para amostras independentes. 


\section{Resultados Empíricos}

$\mathrm{O}$ teste $F$ procura evidência de que as variâncias entre dois grupos são iguais ou não. A partir dessa constatação, é possível selecionar o teste $t$ (para diferença ou igualdade de variâncias), cuja aplicação consiste em verificar a hipótese formulada para as médias entre os grupos: maiores e menores unidades empresariais.

Tabela 5: Teste F de Variância entre Grupos

\begin{tabular}{|c|c|c|c|c|c|}
\hline \multirow{2}{*}{ Variáveis } & \multicolumn{2}{|c|}{ Grupo } & \multirow{2}{*}{$F$} & \multirow{2}{*}{$F$ (crítico) } & \multirow{2}{*}{$\begin{array}{l}P \text {-value } \\
\alpha=0,05\end{array}$} \\
\hline & Menores & Maiores & & & \\
\hline \multicolumn{6}{|l|}{ Média } \\
\hline Total do ativo & 32 & 165 & 10,87 & 1,6899 & 0,002 \\
\hline Volume de vendas & 36 & 161 & 14,55 & 1,6899 & $<0,005$ \\
\hline \multicolumn{6}{|l|}{ Mediana } \\
\hline Total do ativo & 98 & 99 & 11,62 & 1,5299 & 0,001 \\
\hline Volume de vendas & 98 & 99 & 9,40 & 1,5299 & 0,003 \\
\hline
\end{tabular}

Nível de significancia: 0,05

Conforme se observa na Tabela 5, o teste $F$ rejeitou a hipótese (Ho) de igualdade entre as variâncias dos grupos. Utilizou-se, portanto, o teste t para variâncias diferentes, para testar se a média do retorno do grupo de 'maiores empresas' é superior à média do retorno do grupo 'menores empresas' (Tabela 6).

\section{Tabela 6: Teste t para Variâncias Diferentes}

\begin{tabular}{lccc}
\hline \multicolumn{1}{c}{ Variáveis } & t-student & Teste Ho & $\begin{array}{c}\mathrm{p} \text {-value } \\
\alpha=0,05\end{array}$ \\
\hline $\begin{array}{l}\text { Média } \\
\text { Total do ativo }\end{array}$ & 2,00 & Não rejeita & 0,975 \\
Volume de vendas & 3,58 & Não rejeita & 0,999 \\
\hline Mediana & & & \\
Total do ativo & 2,68 & Não rejeita & 0,996 \\
Volume de vendas & 2,61 & Não rejeita & 0,995 \\
\hline
\end{tabular}

t crítico: $-1,960$

Os resultados no teste de médias indicam que se pode aceitar a hipótese deste trabalho (Ho), dado que a característica tamanho empresarial está positivamente relacionada com o retorno das unidades empresariais no mercado brasileiro. 
Os testes demonstraram que os retornos sobre o ativo dos grupos de maiores unidades empresarias possuíam retornos superiores às menores empresas do mercado brasileiro, isso independentemente da variável contábil utilizada como tamanho (total do ativo ou receita de vendas). Portanto, a força 'Barreira de Entrada' da teoria da estratégia do posicionamento, está positivamente relacionada com os retornos das unidades empresariais, quando monitoradas a partir de dados das demonstrações contábeis no mercado brasileiro.

\section{Conclusões e Sugestóes para Futuras Pesquisas}

O estudo da relação entre barreiras de entrada e o retorno empresarial no mercado brasileiro, a partir de dados das demonstrações contábeis, busca identificar se os conceitos da teoria do posicionamento são aderentes ao mercado brasileiro, no quesito 'barreira de entrada', a partir da relação entre o tamanho (proxy para barreira de entrada) e o retorno das unidades empresariais.

Para aplicar os testes, foram utilizadas informações das demonstrações contábeis. Para o tamanho empresarial, utilizaram-se as variáveis Ativo total e a Receita de venda; e, para o retorno empresarial, utilizou-se a variável Lucro líquido sobre o Ativo (retorno contábil). Essas variáveis relacionadas dão indicativos contábeis do retorno empresarial e seus desdobramentos fornecem indicativos para o monitoramento da vantagem competitiva empresarial.

Relacionar parâmetros contábeis com as teorias da estratégia é possível, à medida que é percebido que o objetivo da escola do posicionamento é analisar uma indústria, utilizando-se como parâmetro de posicionamento competitivo a rentabilidade empresarial, considerando ainda que, para uma unidade empresarial alcançar tais retornos superiores, depende de suas características internas características tecnológicas (ativos) e características econômicas (vendas) para competir em seu mercado (rentabilidade: medida de posicionamento).

Os resultados da pesquisa indicam que, em média, existe relação positiva entre o tamanho (barreira de entrada) e o retorno da unidade empresarial no mercado brasileiro.

Tal constatação tem sustentação no arcabouço teórico pesquisado, visto que o tamanho da unidade empresarial garante à firma uma posição de mercado mais forte e segura, em comparação com seus competidores, fornecedores e clientes. $\mathrm{Na}$ medida em que a firma pode ganhar ou controlar seus concorrentes, tem maior espaço de manobra e mais influência sobre decisões do setor ${ }^{(8)}$. 
Contudo, objetivamente, a característica tamanho para a unidade empresarial é considerada importante não só por estar no topo ou próximo dele, em termos de participação de mercado, mas por refletir a capacidade da firma de competir eficientemente e de se beneficiar das economias de escala. Entretanto, "[...] não está claro que a obtenção de uma maior participação de mercado provoca necessariamente uma maior lucratividade e uma posição competitiva mais forte" (Burnard \& Welsch, 1958; Bloom \& Kloter, 1975 como citado em Thompson \& Formby, 1998; Kaplan, Dirlam, \& Lanzilotti, 1958).

No desenvolvimento das pesquisas, foram observados alguns pontos considerados relevantes para trabalhos subseqüentes:

- realizar estudo da relação entre as demais forças (da estratégia competitiva) e o retorno empresarial e sua aderência no mercado brasileiro, a partir de dados das demonstrações contábeis, abordando a inter-relação entre as forças;

- aplicar o estudo das teorias do posicionamento, setorizando os mercados brasileiros, identificando em quais setores essa análise é relevante para explicar a rentabilidade;

- aplicar o estudo das teorias do posicionamento no mercado brasileiro, agrupado em setores da 'nova' e 'velha' economia, identificando onde a análise é relevante para explicar a rentabilidade;

- testar a relevância das variáveis contábeis, margem de lucro e giro do ativo; identificando em que setores a vantagem de custo ou a diferenciação dos produtos são pontos mais significativos para explicar o retorno.

\title{
Artigo recebido em 13.12.2005. Aprovado em 26.05.2006.
}

\section{NOTAS}

\begin{abstract}
${ }^{1}$ Composta por duas abordagens: a tradicional que se preocupa com a análise da indústria por meio do estudo dos componentes: Estrutura, Conduta e Desempenho e suas relações, mas ignora a influência da variável estratégica na estrutura da indústria. A nova abordagem traz a percepção do efeito de feedback no modelo Estrutura-Conduta-Desempenho, que passa a considerar: as ações integradas dos negócios, as diferenças na qualidade de informação e a estratégia das organizações, contribuindo para que o modelo absorva características dinâmicas.
\end{abstract}

${ }^{2}$ De acordo com Iudícibus et al. (2003), "certos conceitos são constatações sobre o ambiente (cenário) em que a Contabilidade atua e constituem a razão de ser de vários outros conceitos que se seguem" (Por exemplo, os Postulados Ambientais da Entidade e da Continuidade). "Outros, na verdade, complementam, explicam, delimitam e restringem a aplicação dos demais; daí serem de uma hierarquia menor", como, por exemplo, os Princípios Propriamente Ditos e as Convenções. "Os 
princípios propriamente ditos representam a resposta da disciplina contábil aos postulados, uma verdadeira postura filosófica e também prática diante do que antes apenas contemplávamos e admitíamos (os postulados). Os princípios (...) delimitam como a profissão irá, em largos traços, posicionar-se diante da realidade social, econômica e institucional admitida pelos Postulados. Já as convenções ou restrições, como a própria denominação indica, representam, dentro do direcionamento geral dos Princípios, certos condicionamentos de aplicação, numa ou noutra situação prática" (p. 53).

${ }^{3}$ Mintzberg, H. (2000). Safári de estratégia. Porto Alegre: Bookman, fez um estudo das escolas da estratégia, identificando suas principais formulações e estágios. Esse trabalho adotou a Escola do Posicionamento, que tem por objetivo analisar a estrutura do mercado e posicionar a unidade empresarial.

${ }^{4} \mathrm{O}$ lucro contábil geralmente significa as receitas totais menos os custos incorridos; logo, lucro contábil é um conceito ex post, baseado em transações passadas e nos fatos históricos, enquanto o lucro econômico significa a receita total menos todos os custos - não só despesas efetivamente incorridas pela firma, mas também uma previsão de retorno normal sobre o capital (Thompson \& Formby, 1998).

${ }^{5}$ Tais conclusões fundamentam-se também nas observações de Christensen, Andrews e Bower (como citado em Porter, 1986), que afirmaram: “[...] os pontos fortes e os pontos fracos da empresa podem ser caracterizados pelo perfil de ativos e as qualificações em relação à concorrência, composto por: recursos financeiros, postura tecnológica, identificação da marca, e assim por diante; [...] os valores pessoais de uma organização são as motivações e as necessidades dos seus principais executivos e de outras pessoas responsáveis pela implementação da estratégia escolhida; [...] as ameaças e as oportunidades da indústria definem o meio competitivo, com seus riscos conseqüentes e recompensas potenciais [...]" (p. 17). Também fundamentadas nas observações de Porter (1983), quando afirma que a intensidade dessas forças determina a habilidade das firmas de ganhar, em média, retornos sobre o investimento acima do custo de capital. A intensidade de cada uma dessas cinco forças é função da estrutura da indústria, ou das características econômicas e técnicas de uma indústria, ou seja, se a estrutura da indústria estiver constituída por uma concorrência hostil, suas margens tendem a ser mais baixas; por outro lado, se a estrutura tiver uma competição branda por preço, em média os retornos serão mais altos. A estratégia consiste em fazer com que uma unidade empresarial supere o retorno sobre o investimento médio da indústria em que está inserta.

${ }^{6}$ Kolmogorov-Smirnov-Z.

${ }^{7}$ Apresenta sensibilidade à presença de valores extremos.

8 "Outro ponto a se observar, não existe outra medida de sucesso empresarial que tenha maior aceitação do que o crescimento em longo prazo (ou seja, crescimento nas vendas, crescimento na produção e crescimento nos lucros)" (Thompson \& Formby, 1998, p. 170).

\section{RefERÊNCIAS BibliográficAs}

Assaf Neto, A. (2002).

Estrutura e análise de balanços: um enfoque econômico-financeiro, comércio e serviços industriais, bancos comerciais e múltiplos (7a ed.). São Paulo: Atlas.
Beuren, I. (2003).

Como elaborar trabalhos monográficos em contabilidade: teoria e prática. São Paulo: Atlas. 
Brigham, E.,

Gapenski, L., \&

Ehrhardt, M. (2001).

Administração financeira: teoria e prática. São Paulo: Atlas.

Burnard, H. S., \&

Welsch, G. A. (1958).

Business budgeting. New York:

Controllership foundation.

Byrns, R., \&

Stone, G., Jr. (1996).

Microeconomia. São Paulo: Makron Books.

Chambers, R. (1966).

Accounting, evaluation and economic behavior. Texas: Scholars Book.

Farina, E.,

Azevedo, P., \&

Saes, M. (1999).

Competitividade: mercado, estado e organizações. São Paulo: Singular.

Financial Accounting Standards Boards -FASB (1980).

Statement of financial accounting concepts n. 2: qualitative characteristics of accounting information. Norwalk, Co: Author.

Iudícibus, S. (2000).

Teoria da contabilidade (6a ed.). São

Paulo: Atlas.

Iudícibus, S.,

Martins, E., \&

Gelbcke, E. R. (2003).

Manual de contabilidade das sociedades por ações (6a ed.). São

Paulo: Atlas.
Kaplan, A. D. H.,

Dirlam, J. B., \&

Lanzilotti, R. F. (1958).

Princing in big business: a case approach. Washington, D. C.: The Brookings Institution.

Limeira, A. (2004).

Contabilidade para executivos (3a ed.). Rio de Janeiro: FGV.

Lopes, A. (2001).

A relevância da informação contábil para o mercado de capitais: modelo de Ohlson aplicado à BOVESPA. Tese de doutorado, Faculdade de Economia, Administração e Contabilidade da Universidade de São Paulo, SP, Brasil.

Marconi, M. A., \&

Lakatos, E. M. (1999).

Técnicas de pesquisa (4a ed.). São Paulo: Atlas.

Martins, G. (2000).

Manual para elaboração de monografias e dissertações (2a ed.). São Paulo: Atlas.

Philips, E. (1963).

The revolution in accounting theory. The Accounting Review, 38(4), 696708. Recuperado em 16 novembro, 2002, de http://www.jstor.org/ journals/ aom.html

Porter, M. (1981).

The contributions of industrial organization to strategic management. The Academy of Management Review, 6(4), 609-620. Recuperado em 12 novembro, 2002, de http:// www.jstor.org/journals/aom.html 
Porter, M. (1983).

Industrial organization and the evolution of concepts for strategic planning: the new learning. Managerial and Decision Economics, 4(3), 172-180. Recuperado em 12 novembro, 2002, de http:// www.jstor.org/journals/aom.html

Porter, M. (1986).

Estratégia competitiva: técnicas para análise de indústrias e da concorrência (7a ed.). Rio de janeiro: Campus.

Ronchi, L. (1977).

Controladoria financeira (3a ed.). São Paulo: Atlas.
Santanna, D.,

Teixeira, A., \&

Louzada, L. (2003).

A relação entre market-to-book equity e lucros anormais no mercado de capitais no Brasil. Anais do Encontro Nacional dos Programas de PósGraduação em Administração, Atibaia, SP, Brasil, 27.

Thompson, A., \&

Formby, J. P. (1998).

Microeconomia da firma: teoria e prática. Rio de Janeiro: Prentice-Hall do Brasil. 
